\title{
lodine Status of Pregnant Women in Bulgaria
}

\author{
Anna-Maria Borissova ${ }^{1,2}$, Ludmila Ivanova ${ }^{2}$, Boyana Trifonova ${ }^{1,2, ~ *, ~ L i l i a ~ D a k o v s k a ~}{ }^{1}$, \\ Eugenia Mihailova ${ }^{1}$, Mircho Vukov ${ }^{1}$ \\ ${ }^{1}$ Clinic of Endocrinology, University Hospital Sofiamed, Sofia, Bulgaria \\ ${ }^{2}$ Faculty of Medicine, Sofia University St. Kliment Ohridski, Sofia, Bulgaria
}

Email address:

boianatri@abv.bg (B. Trifonova)

${ }^{*}$ Corresponding author

\section{To cite this article:}

Anna-Maria Borissova, Ludmila Ivanova, Boyana Trifonova, Lilia Dakovska, Eugenia Mihailova, Mircho Vukov. Iodine Status of Pregnant Women in Bulgaria. European Journal of Preventive Medicine. Vol. 8, No. 4, 2020, pp. 43-47. doi: 10.11648/j.ejpm.20200804.12

Received: June 1, 2020; Accepted: June 29, 2020; Published: August 4, 2020

\begin{abstract}
Universal iodization of salt on the whole territory in Bulgaria was introduced in 1994. The external evaluation of an International expert group conducted in 2005, placed the country among those who successfully overcame the problem of iodine deficiency. AIM of the present study is to update the data on iodine intake of pregnant women in Bulgaria, given that there have been no studies in the last 8 years. MATERIAL: A total number of 537 pregnant women were recruited in the study with an average age $30.49 \pm 5 \mathrm{y}$, distributed by gestational weeks and according to the intake of (vitamins and minerals preparations) preparations containing vitamins with minerals. The study was conducted as a cross-sectional, multicenter population-based in 10 regions of Bulgaria (a total of 84 settlements), without pre-selection and $98.3 \%$ of the examined pregnant women use Bulgarian iodized salt according to the data from the Questionnaire. METHOD: A spot morning urine samples were collected for determination of urinary iodine concentration. The frozen samples in a special container were transported to the accredited Limbach laboratory in Heidelberg, Germany. The iodine in urine was determined by inductively coupled plasma mass spectrometry (ICP-MS) method. The statistical analysis was performed using standard SPSS 13.0 for Windows. RESULTS: The median urinary iodine concentration (mUIC) for the whole group of pregnant women (n-537) was $170 \mu \mathrm{g} / \mathrm{L}(95 \%$ CI 161.00 177.00). Normal iodine excretion is present in $39.3 \%$, low - in $41.2 \%$ and over-optimal - in $19.6 \%$ of pregnant women. Significantly lower levels of iodine in urine were found in the third trimester of pregnancy compared to the first trimester $(\mathrm{P}<$ $0.012)$ and compared to the second trimester $(\mathrm{P}<0.001)$. The median iodine concentration in pregnant women from the group supplemented with combined vitamins with minerals was significantly higher compared to the group without supplementation175 (95\% CI 166.00 - 199.00) against 149 (95\% CI 123.00 - 168.00), P < 0.021. CONCLUSION: During pregnancy, additional supplementation with combined vitamins with minerals containing iodine is required, regardless of the universal iodization of salt, introduced in Bulgaria for more than twenty-five years.
\end{abstract}

Keywords: Pregnant Women, Universal Salt Iodization, Urinary Iodine Concentration, Supplementation

\section{Introduction}

Iodine deficiency is a serious public health and social problem that affects huge population groups in the so-called "endemic" areas with low iodine content in the environment. High risk groups for low iodine intake are pregnant women and infants, as the trace element is involved in the formation of brain structures and inadequate iodine intake during pregnancy and infancy seriously affects the cognitive development of the fetus and newborn [1-3]. With the introduction of "universal" salt iodization, an effective and inexpensive strategy to increase iodine intake by the general population, the problem of iodine deficiency has been eliminated worldwide [4, 5]. The reference group for assessing the effect of iodine prophylaxis are schoolchildren, aged 6-10 years, and the most convenient indicator for assessing iodine intake is the determination of the concentration of iodine in the urine [6-8]. This biochemical marker is used in the application of appropriate sampling and is a sensitive and specific analytical indicator. Iodine concentration in urine reflects immediate iodine intake and is a reliable screening indicator for population groups for which 
reference intervals have been determined for both school children and pregnant women [9]. However, there are still discussions about the epidemiological criteria for assessing iodine status during pregnancy $[10,11]$. Universal iodization of salt on the whole territory in Bulgaria was introduced in 1994. In 2005, the evaluation of an international expert group acknowledged the country among those who successfully solved the problem of iodine deficiency $[12,13]$. According to international criteria, no additional iodine supplementation is recommended for pregnant women in a country that has eliminated iodine deficiency [14]. Results of national surveys for an assessment the progress of the prevention program conducted in 2003, 2008 and 2012 show that iodine intake in schoolchildren is adequate, but in the small number of pregnant women studied - the median iodine is closer to the lower limit of the reference interval $165.0 \mu \mathrm{g} / \mathrm{L}, 158.5 \mu \mathrm{g} / \mathrm{L}$ and $161.0 \mu \mathrm{g} / \mathrm{L}$, respectively.

The aim of the present study is to update the data on iodine intake in pregnant women in Bulgaria, given that no studies have been performed in the last 8 years.

\section{Study Design}

A cross sectional, multicenter population-based study was conducted from September 25 to November 6, 2019 in 10 regions of Bulgaria (Sofia and Sofia region - Samokov, Pirdop; Smolyan and the region; Gotse Delchev; Gabrovo and the region; Troyan-Apriltsi; Burgas and the region; Stara Zagora and region; Pleven and the region), including small towns and villages from each region or a total of 84 settlements. The regions were not randomly selected. Regions with a known iodine deficiency in the past were included, such as Sofia city, Sofia district, Smolyan, Gotse Delchev, Gabrovo, Troyan, as well as regions with iodine sufficiency - Burgas, Stara Zagora, Pleven and their districts. The study was conducted with the assistance of 104 endocrinologists and gynecologists from the selected areas. From their lists of registered pregnant women, a total of 630 women were invited to participate corresponding to a recruiting rate of $85.2 \%(n-537)$.

According to the annual reports of the National Statistical Institute (NSI) of Bulgaria in recent years there are usually about 60000 live births per calendar year. This determined the projected number of pregnant women for inclusion in the screening given that up to about $1 \%$ of their total number for the country should be examined. For 2019, the NSI reports 61 538 live births. The current screening includes 537 or $0.87 \%$ of pregnant women for 2019 [15].

\section{Material and Methods}

We studied 537 pregnant women, mean age $30.49 \pm 5$ y [95\% CI: 30.06 - 30.91], median - 30 (18 - 47), [95\% CI: 30 - 31]. Their distribution by age categories was as follows: $18-22$ y$31(5.78 \%), 23-27 \mathrm{y}-114(21.22 \%), 28-32 \mathrm{y}-214$ (39.86\%), 33 - $37 \mathrm{y}-128$ (23.84\%), 38 - 42 y - 46 (8.56\%), 43 - $47 \mathrm{y}-4(0.74 \%)$. The examined pregnant women were distributed by trimesters according to the gestational week, as follows: first - 109 (20.3\%), second - 269 (50.1\%), third $159(29.6 \%)$.

All participants signed an informed consent, approved by the local Ethics Commission at Sofiamed University Hospital, Sofia University "St Kliment Ohridski", and it was prepared in accordance with ethical standards according of the Helsinki-1964 Declaration and its later additions.

Each pregnant woman filled in a Questionnaire personally with the assistance of a specially designated medical person from the "face to face" team in order to correctly collect data on pregnancy history, intake of combined vitamins and minerals, other medications by type and dose, available thyroid or other diseases. Pregnant women were admitted to the screening at random without pre-selection, as $458 / 537$ $(85.28 \%)$ of them took medication [Magnesium supplements - 125 (23.27\%), Acid Folic - 118 (21.9\%), Micronized progesterone - $23(4.2 \%)$, Iron supplements - 64 (11.9\%), Antispasmodics- 32 (5.9\%), Aspirin - 30 (5.5\%), Low molecular weight heparins - $27(5.0 \%)$, Levothyroxine -79 $(14.7 \%)$, Methyldopa $-4(0.7 \%)]-$ alone or in various combinations. However, mainly in $50.46 \%$ (271/537) of the cases these were combined preparations containing vitamins and minerals taken alone or together with other medications, which is according to the protocol of gynecologists and thus provides $150 \mu \mathrm{g}$ iodine per day. The most common drugs are magnesium, folic acid and iron (57.1\%), while the other drugs are given to individual pregnant women in order to preserve the pregnancy and bring it to a successful delivery antispasmodics, progestin, and anticoagulants. Levothyroxine substitution was found in $79(14.7 \%)$ pregnant women with a known thyroid disease. All participants were of Caucasians, with no evidence of liver, kidney disease or evidence of malabsorption. Pregnant women had followed their usual daily routine in the previous months.

After completing the personal questionnaire, the actual weight and height were measured for each pregnant woman. The pre-pregnancy weight was also registered in the Questionnaire. The body mass index (BMI $-\mathrm{kg} / \mathrm{m}^{2}$ ) before pregnancy and the current one were calculated. Data on dietary supplement use were obtained from Questionnaire, and women were classified as supplement users (using combined vitamins containing $\geq 150 \mu \mathrm{g}$ iodine/day) and nonsupplement users. The cut-off of $150 \mu \mathrm{g}$ was chosen in accordance with the recommended level for iodine supplementation during pregnancy in many countries $[16,17]$ and as the most popular combined vitamin with minerals tablets in our country contain $150 \mu \mathrm{g}$ iodine.

The main indicators that determine the presence of iodine deficiency are: the concentration of urinary iodine, TSH level, thyroid size (volume). The first most important is the amount of iodine in the urine, which reflects the intake of iodine with food $(90 \%$ is excreted passively in the urine depending on estimated glomerular filtration rate, eGFR) [18]. Thus, the concentration of iodine in urine (Urinary iodine concentration, UIC) in a sustained diet represents the balance between dietary intake, thyroid iodine extraction, total thyroid hormone depot and GFR. 


\subsection{Laboratory Test}

Urinary iodine concentration was determined. The Pregnant women gave a single portion of the morning fresh midstream urine $\sim 20 \mathrm{ml}$ using the clean plastic cups to test iodine. The samples were immediately transported at room temperature in neutral monocuvets to the Central Laboratory (for transport shorter than $8 \mathrm{~h}$, they were transported a room temperature, which does not influence their quality) and the aliquots of all urine samples were frozen at $-20^{\circ}$ until analysis. The next day the frozen samples were transported in special containers to the accredited Limbach laboratory in Heidelberg, Germany. The analysis was performed using the accredited inductively coupled plasma mass spectrometry (ICP-MS) method with the following characteristic: linearity in the range of $0-4000 \mu \mathrm{g} / \mathrm{l}$, precision in the series at $304 \mathrm{mcg} / \mathrm{l} \mathrm{RSD} 0.8 \%$, inter-assay $\mathrm{SNU}=304 \mu \mathrm{g} / \mathrm{l}, 15$ shifts, RSD 4.5\%; accuracy percentage deviation from adjusted nominal value of the certified reference material SeronormTM Trace Elements urine (SNU) $(304 \mu \mathrm{g} / 1): 4.0 \%$ (data set $=4 \times 12)$, recovery $104 \%$. The results are presented in $\mu \mathrm{g} / \mathrm{L}$.

\subsection{Statistical Processing}

Statistical analysis was performed using standard SPSS 13.0 for Windows: descriptive statistics (mean, medians, standard deviation), correlation analysis and analysis of variance (ANOVA, post-hoc test - with Bonferroni alpha correction), using parametrical and non-parametrical methods, including - Chi-Square Test, Fisher's Exact Test, Kolmogorov-Smirnov, Shapiro-Wilk Tests, Levene's Test for Equality of Variances, Student's t-test, Kruskal-Wallis test and Mann-Whitney test. All quantitative variables were presented as mean with standard deviation, median or percentage (unless specified otherwise), p values below 0.05 were accepted as statistically significant.

\section{Results and Discussion}

The median urinary iodine concentration (mUIC) for the whole group of pregnant women (n-537) was $170 \mu \mathrm{g} / \mathrm{L}(95 \%$ CI: 161.00 - 177.00). Figure 1 graphically presents iodine in urine for the whole group of 537 pregnant women.

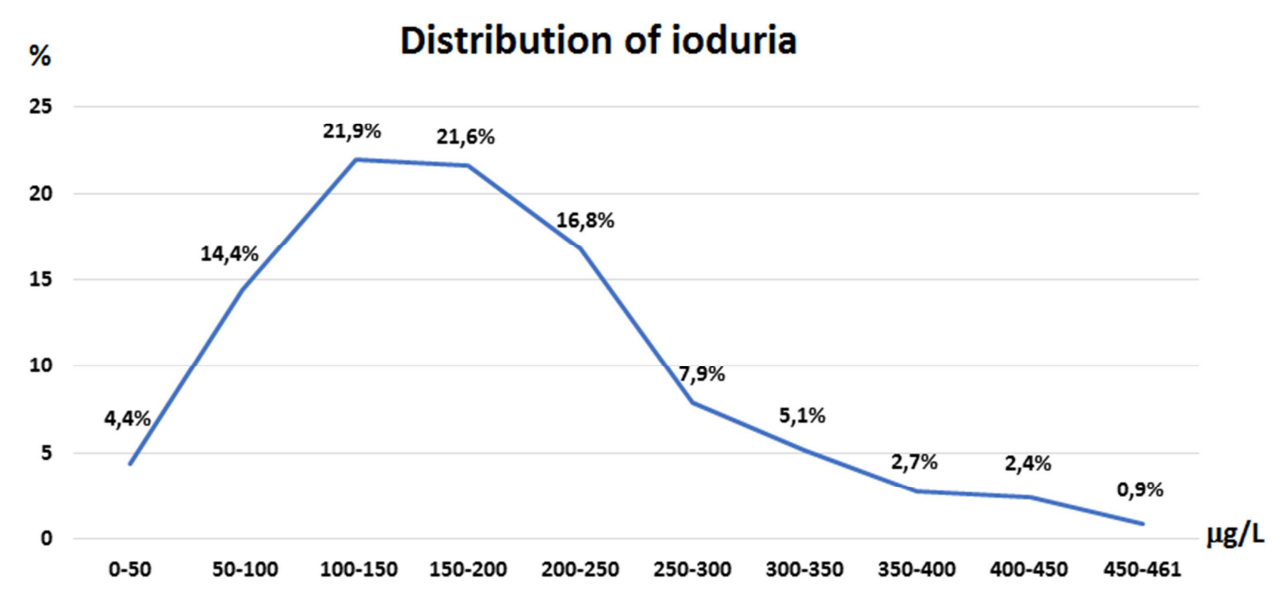

Figure 1. Graphical representation of the distribution of ioduria for the whole group (n-537).

The Table 1 shows the distribution into three main groups according to the size of urinary iodine a. The results show that 211 pregnant women (39.3\%) from the study group had normal iodine excretion in the range of $150-250 \mu \mathrm{g} / \mathrm{L}$, which reflects adequate iodine intake. Below $150 \mu \mathrm{g} / \mathrm{L}-$ lower limit of the reference range of iodine in urine for pregnant women, were 221 women $(41.2 \%)$. There were no cases of excessive iodine intake (iodine in urine $>500 \mu \mathrm{g} / \mathrm{L}$ ), and $105(19.6 \%)$ women had over-optimal iodine intake $(250-497 \mu \mathrm{g} / \mathrm{L})$.

Table 1. Distribution in three main groups according to the level of urinary iodine concentration (UIC) low, normal, over-optimal.

\begin{tabular}{llll}
\hline Parameter & Number & Level $(\boldsymbol{\mu g} / \mathbf{L})$ & $\mathbf{\%}$ \\
\hline Low UIC & 221 & $1-149$ & 41.2 \\
Normal UIC & 211 & $150-249$ & 39.3 \\
Over-optimal UIC & 105 & $249-497$ & 19.6 \\
\hline
\end{tabular}

Table 2 shows UIC by trimester. Significantly lower level of iodine in urine in the third trimester was found compared to the first $(\mathrm{P}<0.012)$ and the second trimester $(\mathrm{P}<0.001)$.
theThese results may be related to the development of the fetal thyroid gland and the need for more substrate to produce hormones by both the mother and already from the fetus.

Table 2. Mean values and median of urinary iodine concentration by trimesters of pregnancy of the study population.

\begin{tabular}{lllll}
\hline Trimester & Mean & Std. Deviation & N & Median \\
\hline First & 185,28 & 94,09 & 109 & 166 \\
Second & 195,13 & 97,68 & 269 & 185 \\
Third & 156,97 & 81,86 & 159 & 145 \\
Total & 181,88 & 93,84 & 537 & 170 \\
\hline
\end{tabular}

The intake of medications and combined vitamins with minerals during pregnancy was additionally analyzed and it was found that only $79(14.7 \%)$ pregnant women did not take anything and the remaining $458(85.29 \%)$ did. It turned out that in the whole studied group of pregnant women (n-537) the most commonly taken drugs were the combined vitamins with minerals - $271(50.47 \%)$. It was specified that among 458 pregnant women taking medication, 271 of them $(59.17 \%)$ 
took combined vitamins with minerals alone or together with other medications (in over $57 \%$ of cases it was folic acid, magnesium, iron, antispasmodic for successful completion of pregnancy and following a standard protocol). Pregnant women under the substitution of combined vitamins with minerals took another $150 \mu \mathrm{g}$ of iodine in addition to the usual diet. Therefore, three groups were formed:

1. Group 1 - pregnant women not taking anything ( $\mathrm{n}-79)$

2. Group 2 - pregnant women taking combined vitamins with minerals - alone or with other medications ( $\mathrm{n}$ - 271)

3. Group 3 - pregnant women taking any medication but not combined vitamins with minerals ( $\mathrm{n}-187$ )

Table 3 divides pregnant women from the three groups described according to medication intake.

Table 3. Distribution of pregnant women according to the use of medications.

\begin{tabular}{llll}
\hline Group & Group 1 & Group 2 & Group 3 \\
\hline & $\begin{array}{l}\text { Not taking } \\
\text { anything }\end{array}$ & $\begin{array}{l}\text { Taking } \\
\text { Vitamins }\end{array}$ & $\begin{array}{l}\text { Taking other } \\
\text { medica tions }\end{array}$ \\
\hline $\begin{array}{l}\text { number } \\
\text { Mean }\end{array}$ & 79 & 271 & 187 \\
$\mathrm{SD}$ & 158.0 & 191.8 & 176.7 \\
$\begin{array}{l}95 \% \text { Confidence Interval } \\
\text { for Mean }\end{array}$ & 92.8 & 95.5 & 89.5 \\
$\begin{array}{l}\text { Median } \\
95 \% \text { Confidence Interval } \\
\text { for Median }\end{array}$ & $137.1-178.9$ & $180.3-203.2$ & $163.7-189.7$ \\
$<149 \mu \mathrm{g} / \mathrm{L}$ & 149 & 175 & 170 \\
$\begin{array}{l}150-249 \mu \mathrm{g} / \mathrm{L} \\
>250 \mu \mathrm{g} / \mathrm{L}\end{array}$ & $53.1 \%$ & $36.9 \%$ & $42.2 \%$ \\
\hline & $32.9 \%$ & $39.4 \%$ & $41.7 \%$ \\
& $13.9 \%$ & $23.6 \%$ & $16 . \%$ \\
\hline
\end{tabular}

The results of UIC presented in the table 3 show that nearly $1 / 3(32.91 \%)$ of pregnant women who have normal iodine excretion do not take any mineral-vitamin supplements. Probably the normal iodine excretion is a result of the universal salt iodization, which includes also the use of iodized salt by the food processing industry (bread, cheese, sausages, etc). Universal iodization of salt in Bulgaria was introduced in 1994 and in 2005 Bulgaria was declared a country that successfully eliminated deficiency among the population [12, 13]. It turns out that the median iodine concentration of pregnant women of group 2 (with supplementation) is significantly higher than in group 1 (without supplementation) [175 (95\% CI: 166.00 - 199.00) vs. 149.00 (95\% CI: 123.00 - 168.00), $\mathrm{P}<0.021$ ], figure 2.

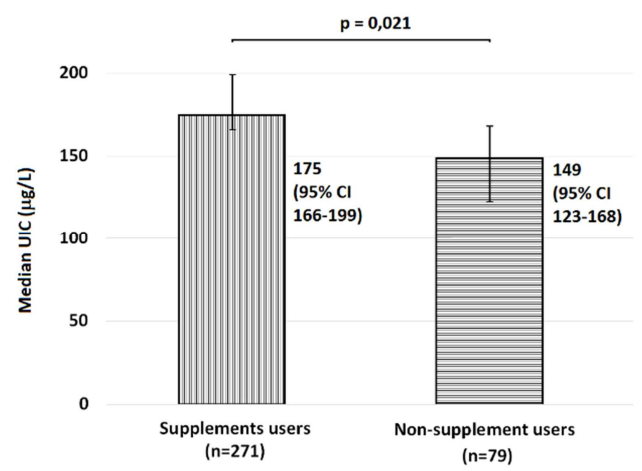

Figure 2. Comparison of median (95\% Confidence Interval for Median) between groups 1 and 2 .
As can be seen from Table 3, a comparison between Group 1 and Group 2 revealed a difference between the frequency of urinary iodine in the subgroup $<149 \mu \mathrm{g} / \mathrm{L}$, which is logically significantly more common in Group 1 (non-supplemented) than in Group 2 (supplemented with combined vitamins with minerals) - 53.17\% against $36.90 \%, \mathrm{P}<0.01$. The frequency of high iodine excretion in the subgroup $>250 \mu \mathrm{g} / \mathrm{L}$, on the contrary, was significantly higher in Group 2 (supplemented with combined vitamins with minerals) compared to Group 1 (not supplemented) $23.62 \%$ vs. $13.92 \%, \mathrm{P}<0.05$.

A special place was given in the Questionnaire regarding the type of salt used in the household -Bulgarian iodized table salt, Himalayan salt or combination of both types of salt It turned out that $483(90.45 \%)$ of all pregnant women use Bulgarian iodized salt, $9(1.69 \%)$ - Himalayan salt and 42 $(7.86 \%)$ - both types of salt. Obviously, the percentage of pregnant women who do not use Bulgarian iodized salt is negligible $-1.69 \%(\mathrm{n}-9)$ and this is an excellent certificate for the Bulgarian population $-98.31 \%$ cook with iodized salt.

Moreover, the recommendations for reducing salt intake and using only iodized salt instead of any other non-iodized varieties remain disputable $[19,20]$.

\section{Conclusion}

The study for evaluation of the current iodine intake of pregnant women under the circumstances of eliminated iodine deficiency by the universal iodization of salt allows to draw several main conclusions. Mass iodine prophylaxis, involving the use of iodized salt in food production and for direct use, provides adequate iodine intake even from population groups with increased needs, such as pregnant women proven to have normal iodine excretion.

Despite the effectiveness of universal iodization of salt and in particular the exclusive use of only iodized salt in the food industry, during pregnancy it is recommended to take additional iodine-containing combined preparations, proven by iodine excretion closer to the optimal reference values for population assessment in the supplemented group.

Due to the widespread recommendation to reduce salt consumption (iodized and non-iodized), including during pregnancy, it is appropriate to recommend to all pregnant women to be supplemented with iodine-containing preparations of vitamins and minerals, regardless of the proven successful elimination of iodine deficiency in Bulgaria.

\section{Conflicts of Interests}

All the authors do not have any possible conflicts of interest.

\section{Acknowledgements}

The authors thank the endocrinologists and 
obstetrician/gynecologists who provided local support: V. Jotova (Troyan), S. Dimitrova (Gabrovo), Anchev (Gabrovo), Mitev (Gabrovo), A. Popov (Goce Delchev), A. Andreev (Samokov), E. Apostolova (Smolyan), M. Hubshev (Smolyan), S. Dimitrov (Pirdop), R. Naumovska (Pleven), M. Manuelyan (Burgas), K. Kirovakov (Burgas), K. Venkova (Sofia), M. Angelova (Stara Zagora), R. Velev (Sofia), I. Sigridov (Sofia), B. Bogoslovova (Sofia)... total 104 specialists in the country. Technical support: T. Kornilova (Sofia), Z. Metodieva (Sofia), J. Georgieva (Sofia), H. Atanasova (Burgas), I. Ilieva (Stara Zagora).

This work was supported by grants from the Bulgarian Society of Endocrinology as part of the National Epidemiological Program for Pregnant Women in Bulgaria 2019.

\section{References}

[1] Bath SC. (2019). The effect of iodine deficiency during pregnancy on child development. Proc Nutr Soc 78 (2): 150-160. doi: 10.1017/S0029665118002835. Epub 2019 Jan 15.

[2] Skeaff SA. (2011). Iodine Deficiency in Pregnancy: The Effect on Neurodevelopment in the Child Nutrients 3 (2): 265-273. Published online 2011 Feb 18. doi: 10.3390/nu3020265.

[3] Zimmermann MB. (2012). The Effects of Iodine Deficiency in Pregnancy and Infancy. Pediatric and Perinatal Epidemiology 26 (Suppl. 1), 108-117.

[4] Andersson M1, de Benoist B, Rogers L. (2010). Epidemiology of iodine deficiency: Salt iodisation and iodine status. Best Pract Res Clin Endocrinol Metab 24 (1): 1-11. doi: 10.1016/j.beem.2009.08.005.

[5] Iodine status worldwide: WHO global database on iodine deficiency. Geneva: World Health Organization; 2004. (http://whqlibdoc.who.int/publications/2004/9241592001.pdf, accessed 20 May 2020.

[6] UNICEF. Guidance from Monitoring of Sal Iodization Programs and Determination of Population Iodine Status, 2015.

[7] UNICEF, PAMM. Urinary Iodine Assessment: A Manual on Survey and Laboratory Methods. PAMM: Washington, DC; 2000.

[8] WHO/UNICEF/ICCIDD. Assessment of iodine deficiency disorders and monitoring their elimination: a guide for programme managers. 2007 , $3 \mathrm{rd} \mathrm{ed}$.
[9] WHO/UNICEF/ICCIDD. A practical guide to the correction of iodine deficiency. Wageningen: International Council for the Control of Iodine Deficiency Disorders; 1990.

[10] Pallavi Panth, Gena Guerin and Nancy M. DiMarco. (2019). A Review of Iodine Status of Women of Reproductive Age in the USA. Biol Trace Elem Res 88 (1): 208-220. Published online 2019 Jan 7. doi: 10.1007/s12011-018-1606-5.

[11] World Health Organization. Urinary iodine concentrations for determining iodine status in populations. VMNIS | Vitamin and Mineral Nutrition Information System 2013.

[12] Decree of the Council of Ministers 96/1994 on the introduction of universal iodization of salt in Bulgaria, State Gazette 43 of 1994.

[13] Review of Progress towards Sustained Optimal Iodine Nutrition in Bulgaria. Report by a team of experts on behalf of the Network for Sustained Elimination of Iodine Deficiency, ed by Tz. Timcheva, SMART Publ. 2006. pp32.

[14] Zimmermann, MB. (2015). Iodine deficiency in pregnant women in Europe. Lancet Diabetes Endocrinol S2213-8587 (15) 00263-6. Published Online, August 10, 2015. http://dx.doi.org/10.1016/.

[15] National Statistical Institute, Number of Live Births Children 2019.

[16] Lazarus J, Brown RS, Daumerie C, Hubalewska-Dydejxzyk A, Negro R, Vaidya B. (2014). 2014 European Thyroid Association guidelines for the management of subclinical hypothyroidism in pregnancy and in children. Eur Thyroid J 3 (2): 76-94. https://doi.org/10.1159/00036 2597.

[17] Alexander EK, Pearce EN, Brent GA, Brown RS, Chen H, Dosiou C, Grobman WA, Laurberg P, Lazarus JH, Mandel SJ, Peeters RP, and Sullivan S. (2017). 2017 Guidelines of the American Thyroid Association for the diagnosis and management of thyroid disease during pregnancy and the $\begin{array}{llll}\text { postpartum. } & \text { Thyroid } 27 & \text { (3): } & 315-389\end{array}$ https://doi.org/10.1089/thy.2016.0457.

[18] Soldin OP. (2002). Controversies in urinary iodine determinations. Clin Biochem 35: 575-579.

[19] Joint strategies for salt iodization and salt reduction in public health. Excerpt from a report of a joint technical meeting convened by the World Health Organization and the George Institute for Global Health in collaboration with the ICCIDD Global Network in Sydney, Australia, 25-27 March 2013. IDD Newsletter, May 2014.

[20] World Health Organization. Global status report on noncommunicable diseases. Geneva, 2010. http://www. who.int/nmh/publications/ncd_report_full_en.pdf. 